\title{
Activity Limitations in Patients with Axial Spondyloarthritis: A Role for Fear of Movement and (Re)injury Beliefs
}

\author{
Thijs W. Swinnen, Johan W.S. Vlaeyen, Wim Dankaerts, René Westhovens, and Kurt de Vlam
}

\begin{abstract}
Objective. To determine whether fear of movement and (re)injury [FOM/(R)I] beliefs, measured with the Tampa Scale for Kinesiophobia 11-item version (TSK-11), influence activity limitations and mediate the relationship between pain severity and activity limitations in axial spondyloarthritis (axSpA).

Methods. In 173 patients with axSpA, these data were collected: sex, body mass index, disease duration, medication, activity limitations (BASFI; Bath Ankylosing Spondylitis Functional Index), disease activity [Bath Ankylosing Spondylitis Disease Activity Index (BASDAI); BASDAIinf, items 5 and 6; BASDAIpain, items 2 and 3; C-reactive protein and physician's global assessment], spinal mobility (BASMI; Bath Ankylosing Spondylitis Metrology Index), and FOM/(R)I (TSK-11). Scaling assumptions and reliability of TSK-11 were tested with item-to-total correlations, item variances, and Cronbach's alpha coefficient. Hypothesis testing determined TSK-11's construct validity. Multiple linear regression showed the contribution of TSK-11 to BASFI (enter and backward modeling). Mediation by TSK-11 was analyzed (bias-corrected bootstrapping and Sobel test).

Results. Adequate scale (Cronbach's alpha $=0.80$ ) and item internal consistency (range item-scale correlations $0.41-0.58$, except for item $5, \mathrm{r}=0.23$ ), equal item-scale correlations, and item variances were found for TSK-11. Construct validity was confirmed, except for the hypothesized positive relationship between TSK-11 and BASMI. Regression models (enter method, adjusted $\mathrm{R}^{2}$ range $53-74 \%$ ) consistently identified TSK-11 as a determinant of BASFI ( $\beta$ range 0.155 to $0.321, \mathrm{p}<0.05$ ), although BASMI ( $\beta$ range 0.441 to 0.537 ) and disease activity ( $\beta$ range 0.243 to $0.571, \mathrm{p}<0.05$ ) were the largest determinants. TSK-11 partially mediated the BASDAIpain/BASFI relationship $(\mathrm{B}=0.107$; Sobel test, $\mathrm{p}=0.004$; bias-corrected CI 0.046-0.197).

Conclusion. TSK-11 is a promising and valid tool to assess fearful beliefs in relation to activity limitations in axSpA. Future research applying TSK-11 may reveal FOM/(R)I as a novel treatment target in axSpA. (First Release November 15 2017; J Rheumatol 2018;45:357-66; doi:10.3899/jrheum.170318)
\end{abstract}

\section{Key Indexing Terms: ANKYLOSING SPONDYLITIS INFLAMMATION}

PSYCHOLOGY
DISABILITY MOBILITY
Axial spondyloarthritis (axSpA) is a chronic rheumatic disease driven by inflammation and damage (pathological bone formation and/or erosion) dominantly at spinal synovioentheseal joint regions ${ }^{1,2}$. Clinically, axSpA manifests as sacroiliitis and spinal inflammation at the anterior vertebral

From the Division of Rheumatology, University Hospitals Leuven; Skeletal Biology and Engineering Research Center, Department of Development and Regeneration, KU Leuven; Health Psychology, Department of Behavior, Health and Psychopathology, KU Leuven, Belgium; Behavioral Medicine, Clinical and Psychological Science, Faculty of Psychology and Neuroscience, Maastricht University, Maastricht, the Netherlands; Musculoskeletal Rehabilitation Research Unit, Department of Rehabilitation Sciences, KU Leuven, Belgium.

Grant support from the Division of Rheumatology, University Hospitals Leuven; Fonds voor Wetenschappelijk Reuma Onderzoek (FWRO, grant number 3M140121), Brussels, Belgium. J.W. Vlaeyen is supported by the "Asthenes" longterm structural funding - Methusalem grant ( $\mathrm{nr}$. METH/15/011) by the Flemish Government, Belgium.

T.W. Swinnen, PT, MSc, Doctoral research fellow, Division of Rheumatology, University Hospitals Leuven, Skeletal Biology and Engineering Research Center, Department of Development and Regeneration, KU Leuven, Musculoskeletal Rehabilitation Research Unit, bodies and posterior structures ${ }^{3}$, but asymmetrical oligoarthritis of large joints and enthesitis are also common peripheral manifestations ${ }^{4}$. Extraskeletal features such as psoriasis, inflammatory bowel disease, or uveitis establish the systemic characteristics of disease. Typical impairments

Department of Rehabilitation Sciences, KU Leuven; J.W. Vlaeyen, PhD, Full Professor, Health Psychology, Department of Psychology, KU Leuven, Behavioral Medicine, Clinical Psychological Science, Faculty of Psychology and Neuroscience, Maastricht University; W. Dankaerts, PT, PhD, Associate Professor, Rehabilitation Sciences, Musculoskeletal Rehabilitation Research Unit, Department of Rehabilitation Sciences, $K U$ Leuven; R. Westhovens, MD, PhD, Full Professor, Division of Rheumatology, University Hospitals Leuven, Skeletal Biology and Engineering Research Center, Department of Development and Regeneration, $K U$ Leuven; $K$. de Vlam, $M D$, PhD, Division of Rheumatology, University Hospitals Leuven, Skeletal Biology and Engineering Research Center, Department of Development and Regeneration, KU Leuven.

Address correspondence to Dr. K. de Vlam, Herestraat 49, Box 7003/13, 3000 Leuven, Belgium.E-mail: kurt.devlam@uzleuven.be Accepted for publication September 8, 2017.

Personal non-commercial use only. The Journal of Rheumatology Copyright () 2018. All rights reserved. 
include inflammatory back pain, spinal stiffness, and mobility restrictions ${ }^{5,6,7}$.

Although the precise etiology of axSpA remains unknown, increased understanding of dysfunctional immunological pathways [e.g., cytokine overexpression of tumor necrosis factor- $\alpha$, interleukin (IL)-17, IL-22, or IL-23] in axSpA has led to the development of highly effective biological disease-modifying antirheumatic drugs (bDMARD) blocking inflammation and possibly aspects of bone formation ${ }^{8,9}$. Unfortunately, only $50-80 \%$ of patients with axSpA can be classified as "responders" to bDMARD, depending on the response criteria used ${ }^{10}$. Biological factors [e.g., high C-reactive protein (CRP) levels, HLA-B27 negativity, or long disease duration] moderately predict nonresponse at best. Thus, a broader bio-psycho-social view is needed to elucidate the mechanisms underlying clinical status and therapy response ${ }^{11}$.

A major attempt to shift from a biomedical to a biopsycho-social framework for the management of axSpA was the development of the World Health Organization's (WHO) International Classification of Functioning, Disability, and Health (ICF) Core Sets for axSpA, endorsed by the Assessment in SpondyloArthritis international Society $(\text { ASAS })^{7,12}$. The WHO/ASAS/ICF Core Set tackles the idea that underlying pathophysiological axSpA disease processes are the sole determinants of functioning ${ }^{6}$ and recognize an equally possible influence of personal (e.g., beliefs, habits) and environmental (e.g., workplace exposure) factors, together referred to as context. Indeed, Brionez, et $a l^{13}$ showed that a composite of personal factors such as depression, arthritis helplessness, internality, and coping explained about $24 \%$ of the variance in activity limitations in axSpA, in contrast to biological factors, which accounted for only $10 \%$ of the variance explained. Similarly, several authors have reported on the association of anxiety and depression (psychological distress) on physical aspects of health-related quality of life in $\operatorname{axSpA}^{14}$.

Unfortunately, prior research did not provide a theoretical framework explaining how psychological variables exert their influence on activity limitations in axSpA. In the broader field of health psychology, the Fear-Avoidance Model of Pain (FAM; Figure 1A) predicts that if pain (associated with movement) is catastrophically appraised, pain-related fear of movement and (re)injury [FOM/(R)I] emanates and leads to a vicious cycle of avoidance behavior, disuse, disability, and depression, and finally more pain ${ }^{15}$. To date, the value of the FAM model, its predictions and therapeutic approaches, remains unexamined in axSpA, while extensive research in subgroups of nonspecific chronic low back pain exhibiting fearful beliefs resulted in effective model-based interventions such as graded exposure in vivo $^{16,17}$. Also, very few studies applied the 17-item Tampa Scale for Kinesiophobia or its shortened 11-item version (TSK-11), the most popular instruments to assess FOM/(R)I beliefs, in arthritis research and none of these involved $\operatorname{axSpA}^{18,19}$.

Therefore, our cross-sectional study aimed to (1) establish the psychometric properties of the TSK-11 scale in axSpA, that is, item-to-total correlation, internal consistency, and divergent construct validity; (2) determine the univariate and multivariate contribution of FOM/(R)I to activity limitations relative to disease activity and spinal mobility, the key "biological" outcome measures in axSpA; and (3) study the mediating role of $\mathrm{FOM} /(\mathrm{R}) \mathrm{I}$ in the relationship between pain and activity limitations, as predicted by the FOM in axSpA (Figure 1A and 1B).

\section{MATERIALS AND METHODS}

Participants. This observational cross-sectional study randomly included 190 subjects with a diagnosis of axSpA according to the ASAS classification criteria $^{20}$, verified by an ASAS expert rheumatologist (KDV) between November 2009 and November 2012. The 5-7 research slots/week available at our outpatient spondyloarthritis clinic were taken by the first patients who signed the informed consent. Exclusion criteria were (1) not being able to autonomously fill in self-reported outcome measures, (2) not being able to understand and speak Dutch, and (3) having other inflammatory or systemic rheumatic conditions. The study protocol and its final reports fulfilled the STROBE (Strengthening The Reporting of Observational Studies in Epidemiology) statement ${ }^{21}$ and was approved by the Medical Ethics Committee of the University Hospitals Leuven (ML 5236).

Anthropometrics and demographics. Age (yrs), sex (male = 1/female = 2), body mass index (BMI; $\mathrm{kg} / \mathrm{m}^{2}$ ), disease duration (yrs), and the use of medication [biologicals, yes $=1 / \mathrm{no}=2$; nonsteroidal antiinflammatory drugs (NSAID), yes $=1 /$ no $=2 ;$ DMARD, yes $=1 /$ no $=2$; corticoids, yes $=1 /$ no $=2$ ] were assessed during a structured interview and a clinical examination, and were also verified by referring to the patient's medical record.

Activity limitations. Patient-reported activity limitations were assessed with the ASAS-endorsed and widely accepted Bath Ankylosing Spondylitis Functional Index (BASFI) questionnaire ${ }^{22}$. Respondents were requested to rate their perceived difficulty in executing daily activities on a 11-point numerical rating scale $(\mathrm{NRS} ; 0=\text { easy, } 10=\text { impossible })^{23}$. A total score was calculated by dividing the sum of all items by 10 , producing a score between 0 (best) and 10 (worst). The psychometric properties of the BASFI in axSpA were well established ${ }^{24}$.

Spinal mobility. The Bath Ankylosing Spondylitis Metrology Index (BASMI) guided the spinal mobility measurement and included 5 clinical tests: cervical rotation [measured with a goniometer (accuracy $2^{\circ}$, Ortec Orthopedics) and a tape measure (accuracy $1 \mathrm{~mm}$ )], lumbar flexion, lumbar side flexion, tragus to wall distance, and intermalleolar distance. For cervical rotation, lumbar side flexion, and tragus to wall distance, the mean of the left and right measurements was taken and all scores were converted according to the BASMI 10 scoring system ${ }^{24}$. The psychometric properties of the BASMI in axSpA are well established $24,25,26$.

Disease activity, pain, and inflammation. Four different measures identified disease activity and inflammation. The Bath Ankylosing Spondylitis Disease Activity Index (BASDAI) demonstrated patient-reported disease activity. The BASDAI questionnaire consisted of 6 items evaluating the severity of fatigue, peripheral and axial pain, localized tenderness, and morning stiffness during the last week. Each item was rated on an 11-point NRS ( $0=$ none, 10 = very severe), with additional anchor words to determine the duration of stiffness $(0 / 1 />2 \mathrm{~h})$ for item 6 . The total score was calculated by dividing the sum of all items by 5 after averaging item 5 and 6 (stiffness evaluation), producing a score between 0 and 10 . The psychometric properties of the BASDAI in axSpA are well established ${ }^{24}$. Patient-reported inflammation was evaluated with the average of BASDAI's stiffness items 5 and 6

Personal non-commercial use only. The Journal of Rheumatology Copyright (C) 2018. All rights reserved 
INJURY

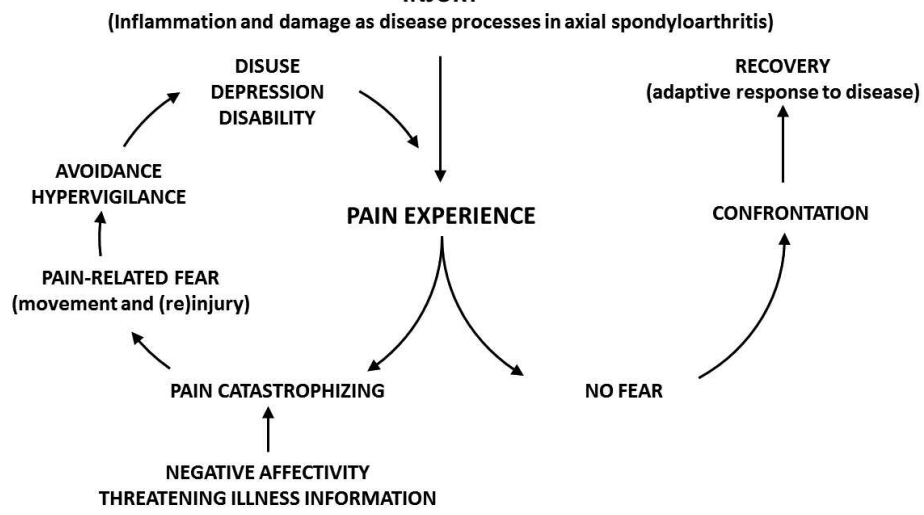

B

c-path (total effect pain on activity limitation, full arrow): $B=.640$ (bCl: .544-.735)

$\mathrm{c}^{\prime}$-path (direct effect without mediator, dashed arrow): $\mathrm{B}=.571$ (bCl: .472-.671)

$R^{2}: .75, p<.001$

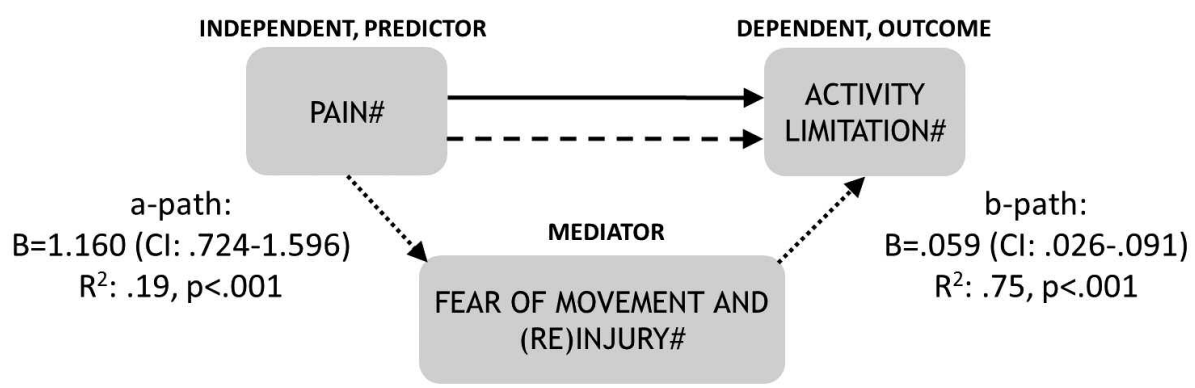

$a * b$ (indirect effect via mediator, dotted arrows): $\mathrm{B}=.068$ (bCl: .029-.123)

Figure 1. Illustration of the fear avoidance model of pain (A) and mediating role of fear of movement and (re)injury (B) in the relationship between pain and activity limitations in axial spondyloarthritis $(n=173) .{ }^{\text {\# }}$ Mediating effect $\left(\mathrm{a} \times \mathrm{b}=\mathrm{c}-\mathrm{c}^{\prime}\right)$ of fear of movement and (re)injury (Tampa Scale for Kinesiophobia 11-item version) in the relationship between pain (average items 2 and 3 of BASDAI) and activity limitations (BASFI) showing unstandardized B weights with 5000 samples bias-corrected bootstrap 95\% CI and explained variance $\left(\mathrm{R}^{2}\right)$ for each path $(\mathrm{p}<0.05)$. BASDAI: Bath Ankylosing Spondylitis Disease Activity Index; BASFI: Bath Ankylosing Spondylitis Functional Index.

(BASDAIinf), as recommended by the ASAS group ${ }^{24}$. Physician global disease activity (PGDA) assessed during the routine rheumatology visit at inclusion represented physician-reported disease activity. PGDA was evaluated using a reliable and valid 11 -point NRS scale $(0=$ none, $10=$ very severe $)^{24}$. CRP (mg/l) served as the laboratory-based disease activity marker ${ }^{24}$. Pain severity (BASDAIpain) was assessed by the average of BASDAI item 2 (overall level of AS neck, back, or hip pain) and item 3 (overall level of pain in joints other than neck, back, or hips) on an 11-point $\mathrm{NRS}^{24}$

Evaluating FOM/(R)I. The Dutch TSK-11 evaluated the patient's FOM/(R)I beliefs using 4-point Likert scales with scoring alternatives ranging from "strongly disagree" to "strongly agree." The psychometric properties of TSK-11 (Supplementary Table 1, available with the online version of this article) are well established across different non-axSpA populations s7,28,29 $^{2}$

Data reduction and statistical analysis. Descriptive data were presented as mean, median, percentile 25 and 75, minimum, and maximum values. Normal distribution of all variables was evaluated with the Shapiro-Wilk test $(\mathrm{p}<0.05)$ and deviated for CRP and PGDA, which were $\mathrm{LOG}_{10}$ transformed to obtain adequate normality of data.

To test the 4 basic scaling assumptions for Likert scales such as
TSK-11 27,30,31, homogeneity was assessed by Cronbach's alpha coefficient with values between 0.70 and 0.90 , indicating adequate scale internal consistency ${ }^{32}$, and corrected item-to-total correlations with values above 0.20 as acceptable and above 0.40 as good item internal consistency ${ }^{30}$. Also, the latter correlations and item variances presented as SD should be roughly equal across items to confirm the equality of item-scale correlations and equality of item variances assumptions. To test the convergent and divergent construct validity of TSK-11, bivariate Pearson product-moment correlations were calculated among TSK-11 and measures of activity limitations, spinal mobility, and spinal pain (significant, positive and moderate $>0.40$, but $<0.80$ correlations expected), and with BMI (positive), disease duration (negative), and age [positive, (non)significant, weak $<0.40$ correlations expected].

Multiple linear regression (enter method) was applied to model BASFI from demographic and anthropometric factors (sex, age, BMI), disease-related characteristics (use of biologicals, NSAID, disease duration, disease activity and inflammation, spinal mobility), and TSK-11. We built BASFI models for disease activity (BASDAI or PGDA and CRP combined), inflammation (BASDAIinf), and spinal pain (BASDAIpain) separately. Adjusted $\mathrm{R}^{2}$ showed each model's explanatory power. Standardized $\beta$

Personal non-commercial use only. The Journal of Rheumatology Copyright $\subset$ 2018 . All rights reserved. 
weights allowed for direct comparison of each variable's contribution to the model. Commonality analysis provided unique and common variance estimates for each determinant and their combinations ${ }^{33}$. Further, a backward elimination procedure with a probability of $\mathrm{F}$ to remove a determinant of $\leq 0.1$ was used to model the BASFI from an optimal set of determinants. To avoid co-linearity, the variance inflation factor (VIF) was set at $<3$ for all analyses. To evaluate the basic tenet of the FAM in axSpA (Figure 1B), the mediating effect of TSK-11 [FOM/(R)I as mediator] in the relationship between BASDAIpain (independent as pain experience) and BASFI (dependent as disability outcome) was determined through the PROCESS macro version 2.13 for SPSS using bias-corrected bootstrap 95\% CI with 5000 samples, and the Sobel test $(\mathrm{p}<0.05)^{34}$. All remaining variables from previous models were entered as covariates. All analyses were performed with SPSS 20.0 (IBM Statistics).

\section{RESULTS}

Demographic data. Of all 190 patients invited, 4 refused to participate because of a lack of time. The number of cases with missing data was $2(1.1 \%)$ for the BASMI; $3(1.6 \%)$ for the TSK-11; 7 (3.8\%) for the BASFI; $6(3.2 \%)$ for the BASDAI, BASDAIpain, and BASDAIinf; 26 for PGDA (14.0\%); and 31 for CRP (16.7\%). Full data across outcome measures were available for 173 patients (6.9\% data loss) for analyses without PGDA and CRP. For models including PGDA or CRP, data for 133 subjects were available (28.4\% data loss). No statistically significant differences were found between the subsamples $(p>0.05)$. Full demographic data were shown in Table 1 and reflected a typical outpatient axSpA sample ${ }^{23}$.
Psychometric properties of TSK-11. An adequate Cronbach's alpha value of 0.80 was found for the TSK-11 scale. Item-to-total correlation coefficients (Table 2 ) showed overall values between 0.41 and 0.58 , except for item TSK-5 ("People aren't taking my medical condition seriously enough"), with an acceptable value of 0.23 . Omitting this item only marginally improved Cronbach's alpha for the TSK-11 scale, so the full scale was included in further analyses (no differences with or without this item included were found for all analyses). Item-to-total correlations were equal across items, as were item variances (Table 2). In sum, scaling assumptions of TSK-11 were confirmed.

Construct validity was confirmed as hypothesized, except for spinal mobility, which correlated positively but weakly $(\mathrm{r}=0.11, \mathrm{p}=0.025)$ with TSK-11. Positive and moderate associations with TSK-11 were found for activity limitations $(\mathrm{r}=0.45, \mathrm{p}<0.001)$, and pain $(\mathrm{r}=0.41, \mathrm{p}<0.001)$, while weak associations $(p>0.05)$ were found with BMI $(r=0.04$, $\mathrm{p}=0.585$, positive $)$, disease duration $(\mathrm{r}=-0.02, \mathrm{p}=0.773$, negative), and age $(r=0.12, p=0.118$, positive $)$. In sum, construct validity was confirmed.

Bivariate and multivariate determinants of activity limitations. Bivariate correlation coefficients revealed TSK-11, BASMI, BASDAI, BASDAIinf, BASDAIpain, PGDA, and age as possible determinants of BASFI (Table 3). All hierarchical regression models consistently identified TSK-11 as an important determinant of BASFI (Table 4$)$ with $\beta$ varying

Table 1. Descriptives for all demographic, anthropometric, and disease-related outcomes in patients with axial spondyloarthritis $(\mathrm{n}=173)$.

\begin{tabular}{|c|c|c|c|c|c|c|c|}
\hline Variables & Mean & $\mathrm{SD}$ & $\mathrm{P} 25$ & Median & P75 & Min & $\operatorname{Max}$ \\
\hline Age, yrs & 42.74 & 12.26 & 31.77 & 42.70 & 52.55 & 19.40 & 73.81 \\
\hline Disease duration, yrs & 13.27 & 11.13 & 3.89 & 10.83 & 21.20 & 0.01 & 53.93 \\
\hline Height, cm & 171.43 & 9.47 & 164.35 & 172.30 & 177.70 & 146.80 & 193.10 \\
\hline Weight, kg & 76.69 & 15.18 & 65.55 & 75.70 & 86.40 & 43.60 & 120.00 \\
\hline $\mathrm{BMI}, \mathrm{kg} / \mathrm{m}^{2}$ & 26.02 & 4.40 & 22.55 & 25.52 & 28.98 & 16.55 & 40.79 \\
\hline BASDAI total $(0-10)$ & 3.85 & 2.17 & 2.10 & 3.70 & 5.40 & 0.00 & 9.80 \\
\hline BASDAI inf $(0-10)$ & 3.63 & 2.74 & 1.50 & 3.00 & 6.00 & 0.00 & 10.00 \\
\hline BASDAI pain $(0-10)$ & 3.91 & 2.18 & 2.25 & 3.75 & 5.50 & 0.00 & 9.75 \\
\hline BASFI (0-10) & 3.66 & 2.36 & 1.80 & 3.40 & 5.60 & 0.00 & 9.80 \\
\hline TSK-11 (11-44) & 24.83 & 6.22 & 20.00 & 25.00 & 30.00 & 11.00 & 38.00 \\
\hline BASMI (0-10) & 3.06 & 1.78 & 1.80 & 2.80 & 3.90 & 0.00 & 8.40 \\
\hline Cervical rotation, $\mathrm{cm}$ & 60.54 & 19.55 & 50.00 & 65.00 & 75.00 & 4.00 & 95.00 \\
\hline Tragus-to-wall, cm & 13.65 & 4.54 & 10.60 & 11.75 & 15.30 & 8.20 & 31.35 \\
\hline Lateral flexion, $\mathrm{cm}$ & 12.33 & 5.53 & 8.20 & 12.50 & 16.50 & 1.05 & 24.45 \\
\hline Intermalleolar distance, $\mathrm{cm}$ & 98.88 & 22.41 & 88.65 & 102.50 & 113.60 & 11.00 & 140.20 \\
\hline Hip internal rotation, $\mathrm{cm}$ & 44.45 & 12.75 & 36.95 & 44.60 & 52.10 & 9.60 & 97.20 \\
\hline Modified Schober, cm & 5.27 & 2.13 & 4.10 & 5.50 & 6.55 & 0.40 & 14.20 \\
\hline \multicolumn{8}{|l|}{ Frequencies $(\%)$} \\
\hline Sex, male/female & $109 / 64(63 / 37)$ & & & & & & \\
\hline NSAID, yes/no & $89 / 84(51 / 49)$ & & & & & & \\
\hline Biologicals, yes/no & $69 / 104(40 / 60)$ & & & & & & \\
\hline Corticosteroids, yes/no & $13 / 160(8 / 92)$ & & & & & & \\
\hline DMARD, yes/no & $72 / 101(42 / 58)$ & & & & & & \\
\hline
\end{tabular}

Height and weight were measured with a stadiometer (Holtain Ltd.) and digital scale (SECA) respectively. P: percentile; Min: minimum; Max: maximum; BMI: body mass index; BASDAI: Bath Ankylosing Spondylitis Disease Activity Index; BASDAI inf: average of stiffness items 5 and 6 of BASDAI; BASDAI pain: spinal pain item of BASDAI; BASFI: Bath Ankylosing Spondylitis Functional Index; BASMI: Bath Ankylosing Spondylitis Disease Metrology Index; TSK-11: Tampa Scale for Kinesiophobia 11-item version; NSAID: nonsteroidal antiinflammatory drugs; DMARD: disease-modifying antirheumatic drugs. 
Table 2. Item-to-total correlations, item variances, and Cronbach's alpha coefficients for the TSK-11 scale and its items in patients with axial spondyloarthritis $(\mathrm{n}=173)$.

\begin{tabular}{lccc}
\hline Variables & $\begin{array}{c}\text { Item-to-total } \\
\text { Correlation* }\end{array}$ & $\begin{array}{c}\text { SD for Each } \\
\text { Item }\end{array}$ & $\begin{array}{c}\text { Cronbach's Alpha } \\
\text { if Item Deleted }\end{array}$ \\
\hline TSK-1 & 0.55 & 1.00 & 0.77 \\
TSK-2 & 0.53 & 1.00 & 0.77 \\
TSK-3 & 0.58 & 0.96 & 0.77 \\
TSK-5 & 0.23 & 1.06 & 0.80 \\
TSK-6 & 0.45 & 0.92 & 0.78 \\
TSK-7 & 0.45 & 0.94 & 0.78 \\
TSK-10 & 0.42 & 1.05 & 0.78 \\
TSK-11 & 0.47 & 1.01 & 0.78 \\
TSK-13 & 0.42 & 0.96 & 0.78 \\
TSK-15 & 0.52 & 0.99 & 0.77 \\
TSK-17 & 0.41 & 0.86 & 0.79 \\
\hline
\end{tabular}

* Correlation of $>0.20$ (acceptable) and $>0.40$ (good) between 1 TSK-11 item and the full TSK-11 scale with this item deleted reflects item internal consistency assumption. ** Roughly equal SD across items reflects item variance assumption. TSK-11: Tampa Scale for Kinesiophobia 11-item version.

from $0.165(\mathrm{n}=177$, BASDAIpain as spinal pain, adjusted $\left.\mathrm{R}^{2}=0.74 ; \mathrm{p}=0.001\right)$ to $0.321(\mathrm{n}=133$, PGDA/CRP as disease activity, adjusted $\mathrm{R}^{2}=0.53, \mathrm{p}<0.001$; Table 3 ). Largest contributions were consistently found for BASMI with $\beta$ ranging from $0.441(\mathrm{n}=133$, BASDAI as disease activity, adjusted $\left.\mathrm{R}^{2}=0.70 ; \mathrm{p}<0.001\right)$ to $0.537(\mathrm{n}=177$, BASDAIinf as inflammation, adjusted $\mathrm{R}^{2}=0.67 ; \mathrm{p}<0.001$ ) and for definitions of disease activity, spinal pain, and inflammation varying from $0.243(\mathrm{n}=133$, PGDA as disease activity, adjusted $\left.\mathrm{R}^{2}=0.53 ; \mathrm{p}<0.001\right)$ to $0.571(\mathrm{n}=177$,
BASDAIpain as spinal pain, adjusted $\mathrm{R}^{2}=0.74 ; \mathrm{p}<0.001$ ). Explanatory power was grossly comparable across models, with slightly lower values when PGDA and CRP were used to measure disease activity (adjusted $\mathrm{R}^{2}=0.53 ; \mathrm{p}<0.001$ ). Unique variance explained was somewhat lower for TSK-11 $\left(\mathrm{R}^{2}=0.02\right.$ to 0.10$)$ than for definitions of disease activity/pain/inflammation $\left(\mathrm{R}^{2}=0.13\right.$ to 0.23$)$ and BASMI $\left(\mathrm{R}^{2}=0.11-0.16\right)$, but its contribution to common variance was more similar (TSK-11 $\mathrm{R}^{2}=0.12-0.19$, disease activity/pain/inflammation $\mathrm{R}^{2}=0.04-0.30$, BASMI $\mathrm{R}^{2}$ $=0.17-0.25$; Supplementary Tables 2 and 3 , available with the online version of this article). Regression models with backward elimination yielded comparable results, with BASMI, disease activity (BASDAI, BASDAIinf), spinal pain (BASDAIpain), and TSK-11 as key determinants of BASFI $(\mathrm{p}<0.001$; Figure 2).

$F O M /(R) I$ beliefs as mediator. The total effect (c-path) of BASDAIpain (independent outcome, pain experience in the FAM model; Figure $1 \mathrm{~B}, \mathrm{n}=173$ ) on BASFI (dependent outcome, disability in the FAM model) was $\mathrm{B}=0.640$ [bootstrap CI (bCI) 0.544-0.735, $\mathrm{R}^{2}=0.75 ; \mathrm{p}<0.001$ ], with a direct effect of $\mathrm{B}=0.571$ ( $\mathrm{c}^{\prime}$-path; bCI $0.472-0.671 ; \mathrm{R}^{2}$ $=0.73 ; \mathrm{p}<0.001)$. BASDAIpain predicted TSK-11 (a-path; $\mathrm{B}=1.160$, bCI $\left.0.724-1.596 ; \mathrm{R}^{2}=0.19 ; \mathrm{p}<0.001\right)$ and TSK-11 predicted BASFI (b-path; $\mathrm{B}=0.059$, bCI 0.026-0.091). The indirect effect of BASDAIpain by mediator TSK-11 on BASFI was significant $\left(\mathrm{a} \times \mathrm{b}=\mathrm{c}-\mathrm{c}^{\prime}\right.$; $\mathrm{B}=0.068$, bCI $0.029-0.123$ ), corresponding to a partially mediated effect (ratio c' path/c-path: 0.068/0.640) of $11 \%$ (B = 0.107, bCI 0.046-0.197; Sobel test, $\mathrm{p}=0.004)$.

Table 3. Bivariate correlations $s^{\#}$ for all continuous modeled variables in patients with axial spondyloarthritis $\left(\mathrm{n}=173^{\S}\right)$.

\begin{tabular}{|c|c|c|c|c|c|c|c|c|c|c|c|}
\hline $\begin{array}{l}\text { 1. Activity limitation } \\
\text { (BASFI, 0-10)) }\end{array}$ & - & $0.45^{* *}$ & $0.61^{* *}$ & $0.71^{* *}$ & $0.55^{* *}$ & $0.71^{* *}$ & $0.19^{*}$ & $0.32^{* *}$ & 0.13 & 0.17 & $0.30^{* *}$ \\
\hline $\begin{array}{l}\text { 3. Spinal mobility } \\
\text { (BASMI, 0-10) }\end{array}$ & $0.61^{* *}$ & $0.17^{*}$ & - & $0.20^{* *}$ & 0.14 & $0.21^{* *}$ & $0.46^{* *}$ & $0.57^{* *}$ & 0.15 & 0.14 & -0.00 \\
\hline $\begin{array}{l}\text { 5. Patient-reported inflamm } \\
\text { (BASDAIinf, 0-10) }\end{array}$ & $\begin{array}{l}\text { nation } \\
0.55^{* *}\end{array}$ & $0.29^{* *}$ & 0.14 & $0.83^{* *}$ & - & $0.72^{* *}$ & -0.00 & 0.00 & 0.06 & 0.11 & $0.43^{* *}$ \\
\hline $\begin{array}{l}\text { 6. Patient-reported pain (BA } \\
\text { pain, } 0-10)\end{array}$ & $\begin{array}{l}\text { ASDAI } \\
0.71^{* *}\end{array}$ & $0.41^{* *}$ & $0.21^{* *}$ & $0.98^{* *}$ & $0.72^{* * *}$ & - & -0.04 & 0.09 & 0.05 & 0.08 & $0.42^{* *}$ \\
\hline 7. Disease duration, yrs & $0.19^{*}$ & -0.02 & $0.46^{* *}$ & -0.03 & -0.00 & -0.040 & - & $0.58^{* *}$ & -0.03 & -0.06 & -0.08 \\
\hline 8. Age, yrs & $0.32^{* *}$ & 0.12 & $0.57^{* *}$ & 0.07 & 0.00 & 0.09 & $0.58^{* *}$ & - & $0.17^{*}$ & -0.03 & -0.08 \\
\hline 11. PGDA, $0-10^{\S}$ & $0.30^{* *}$ & 0.13 & -0.00 & $0.45^{* *}$ & $0.43^{* *}$ & $0.42^{* *}$ & -0.08 & -0.08 & -0.00 & $0.23^{* *}$ & - \\
\hline
\end{tabular}

** $\mathrm{p}<0.01 . * \mathrm{p}<0.05$. ${ }^{\#}$ Pearson product-moment correlation coefficients. ${ }^{\S}$ For analyses including CRP or PGDA, $\mathrm{n}=133$. CRP: C-reactive protein; PGDA: physician global disease activity; BASFI: Bath Ankylosing Spondylitis Functional Index; TSK-11: Tampa Scale for Kinesiophobia 11-item version; BASMI: Bath Ankylosing Spondylitis Metrology Index; BASDAI: Bath Ankylosing Spondylitis Disease Activity Index; BMI: body mass index. 
Table 4. Multivariate models showing the effect of fear of movement and (re)injury beliefs (TSK-11) on activity limitations (BASFI) in patients with axial spondyloarthritis.

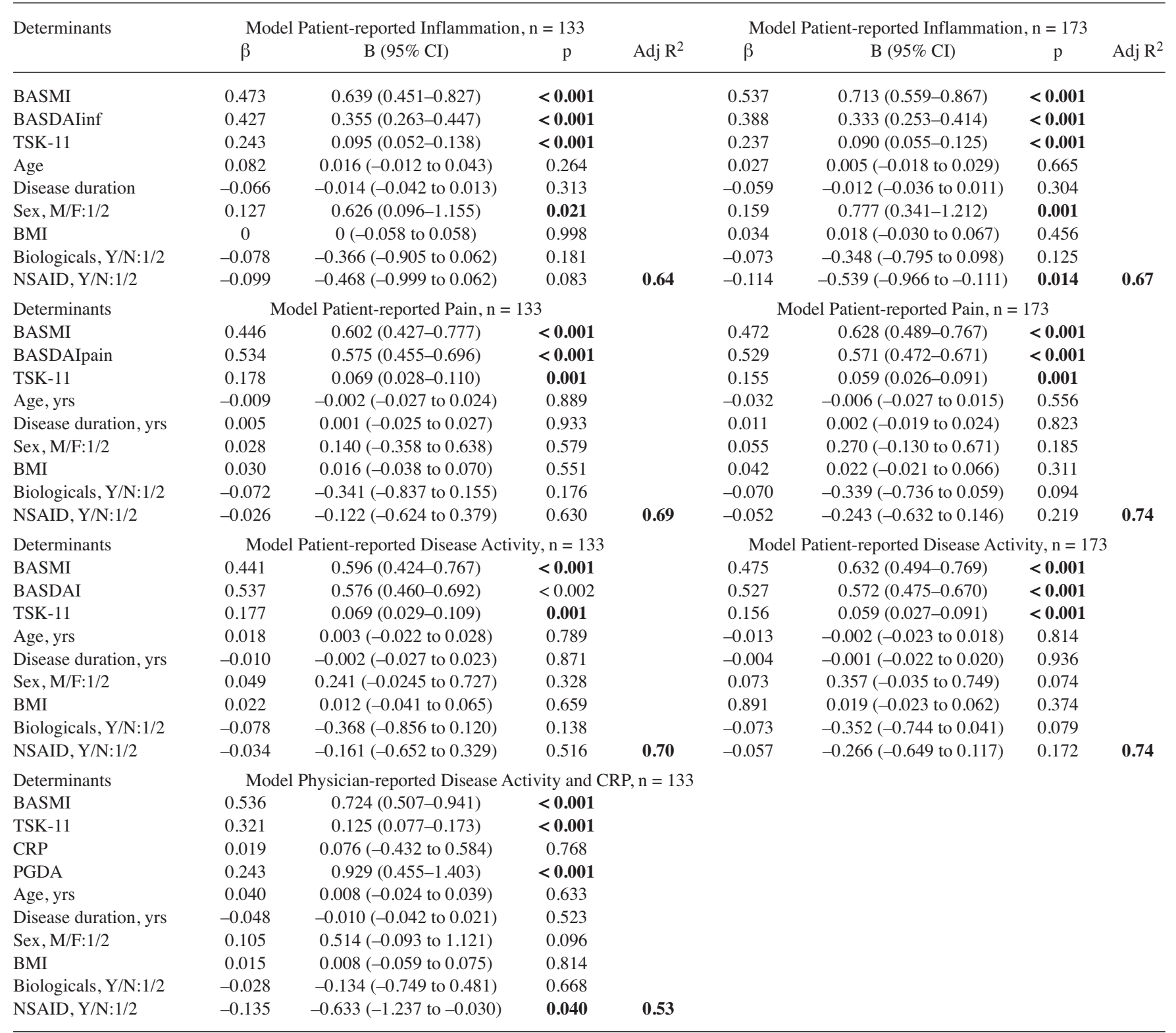

Significant results in bold $(\mathrm{p}<0.05)$. $\beta$ : standardized beta coefficient; B $(95 \% \mathrm{CI})$ : beta coefficient with $95 \%$ CI; BASDAI: Bath Ankylosing Spondylitis Disease Activity Index; BASDAIinf: average item 5, 6 of BASDAI; BASDAIpain: average item 2, 3 of BASDAI; BASFI: Bath Ankylosing Spondylitis Functional Index; TSK-11: Tampa Scale for Kinesiophobia 11-item version; CRP: C-reactive protein; PGDA: physician global disease activity; BMI: body mass index; NSAID: nonsteroidal antiinflammatory drug; BASMI: Bath Ankylosing Spondylitis Metrology Index.

\section{DISCUSSION}

To our knowledge, our current study was the first to investigate the role of $\mathrm{FOM} /(\mathrm{R}) \mathrm{I}$ in patients with axSpA and to establish key psychometric qualities of the TSK-11 in axSpA, that is, its scaling assumptions and divergent construct validity.

In the field of rheumatology, few studies have tapped into the $\mathrm{FOM} /(\mathrm{R}) \mathrm{I}$ or related constructs, especially in axSpA. First, Mielenz, et al ${ }^{19}$ applied item-response theory modeling to establish the reliability and fit of the original 17-item Tampa Scale for Kinesiophobia in patients with self-reported arthritis taking part in an exercise intervention. Similar to previous work on the structural validity of TSK-11 $27,28,35$, they confirmed the misfit of all inversely stated items in the original 17-item version and reduced the number of items to 11. Nevertheless, we preferred the TSK-11 version of Woby, et $a l^{27}$, removing the inversed items $4,8,12$, and 16 , as well as items 9 and 14, given its extensive structural validation 
Model A : BASDAl as patient-reported disease activity

\begin{tabular}{|c|c|}
\hline BASDAI & $\beta: .553 ; \mathrm{p}<.001$ \\
\hline BASMI $.601(.509-.693)$ \\
$\beta: .471 ; \mathrm{p}<.001$ \\
\hline TS:.626(.521-.731) \\
\hline$\beta: .145 ; \mathrm{p}=.001$ \\
\hline $\mathrm{B}: .055(.023-.087)$
\end{tabular}

Adjusted $R^{2}: .74, p<.001$

Model B : BASDAI stiffness items as patient-reported inflammation (BASDAlinfl)

\begin{tabular}{|c|c|}
\hline BASMI & $\beta: .548 ; \mathrm{p}<.001$ \\
\hline BASDAl inflammation & $\beta: .728(.607-.849)$ \\
\hline & $\beta: .387 ; p<.001$ \\
\hline TSK-11 & $\beta: .233(.253-.412)$ \\
\hline Gender & $\beta: .091(.056-.126)$ \\
\hline NSAIDs & $\beta: .157 ; p=001$ \\
\hline & $\beta: .765(.331-1.199)$ \\
\hline
\end{tabular}

Model C : BASDAI pain items as patient-reported pain (BASDAIpain)

\begin{tabular}{|c|c|}
\hline BASDAI pain & $\beta: .551 ; p<.001$ \\
\hline BASMI $.596(.503-.689)$ \\
$\beta: .469 ; p<.001$ \\
\hline BS: .623(.518-.729) \\
\hline$\beta: .143 ; p=.001$ \\
\hline B: .596(.503-.689)
\end{tabular}

Adjusted $\mathrm{R}^{2}: .74, \mathrm{p}<.001$

Figure 2. Multiple linear regression modeling (backward elimination) of activity limitations (BASFI) in patients with axial spondyloarthritis $(\mathrm{n}=173)$. ${ }^{\#}$ Multiple linear regression using backward elimination with a probability of $\mathrm{F}$ to remove a predictor of $\leq 0.1$. $\S$ Apart from standardized $\beta$ regression coefficients $\beta$ also unweighted regressions coefficients B and their corresponding 95\% CI are given, variance inflation factors between 1.018 and 1.162; squared variance explained is given as $\mathrm{R}^{2}$ BASFI: Bath Ankylosing Spondylitis Functional Index (activity limitations); BASMI: Bath Ankylosing Spondylitis Metrology Index 10 percentile version (spinal mobility); BASDAI: Bath Ankylosing Spondylitis Disease Activity Index full scale (disease activity), average items 2-3 (pain), average items 5-6 (inflammation); TSK-11: Tampa Scale for Kinesiophobia 11-item version; NSAID: nonsteroidal antiinflammatory drugs.

across diagnoses ${ }^{29,35}$. The strikingly similar internal consistency (Cronbach's alpha 0.79 vs 0.80 in our study), and comparable item-to-total correlations in general and for possible problem items 5 (0.340 vs 0.229$)$, 13 ( 0.430 vs $0.415)$, and $6(0.340$ vs 0.446$)$ justified this choice ${ }^{27}$. Although TSK-11 showed satisfactory scaling assumptions and construct validity in this study, future research by our group on its test-retest reliability and structural validity is needed and under way.

Second, Berenbaum, et $a^{36}$ qualitatively studied patient's attitudes and beliefs regarding their disease in axSpA. Patients reported "too intense physical activity over a longer period" and "physical or tiring professional activity" as factors causing outbreak of disease, while on the other hand "sports activities and exercise" were believed to attenuate such outbreaks. In this context, it is hypothesized that $\mathrm{FOM} /(\mathrm{R}) \mathrm{I}$ does not represent a "phobic" state toward movement in axSpA, but rather reflects the belief that especially strenuous physical activities relate to increased disease activity. This hypothesis is strengthened by prior research from our group using accelerometry-based monitoring of physical activity in axSpA ${ }^{37}$. This study indeed observed an almost complete lack of (very) vigorous, but not moderate physical activities, suggesting that avoidance of intense movements may have occurred. Also, the current study showed the unique and clinically relevant contribution

$$
\text { Personal non-commercial use only. The Journal of Rheumatology Copyright @ } 2018 \text {. All rights reserved. }
$$


of $\mathrm{FOM} /(\mathrm{R}) \mathrm{I}$ to experienced activity limitations as measured with BASFI. Together, these data seem in line with the FAM predicting the harm of $\mathrm{FOM} /(\mathrm{R}) \mathrm{I}$ beliefs on disability through avoidance ${ }^{15}$ and further corroborate the importance of $\mathrm{FOM} /(\mathrm{R}) \mathrm{I}$ beliefs to explain functioning in axSpA.

Third, Lööf, et al ${ }^{18}$ revealed that $\mathrm{FOM} /(\mathrm{R}) \mathrm{I}$ was associated with male sex, low income, high pain, low health-related quality of life, and low exercise self-efficacy in patients with rheumatoid arthritis participating in the Physical Activity in Rheumatoid Arthritis 2010 exercise intervention. Our TSK-11 results (median 25 with a range of 11-44) indicated that patients with axSpA also exhibit concerns about movement or (re)injury. TSK-11 was, even on a group level, a consistent determinant of BASFI regardless of the regression modeling approach used ${ }^{38}$, the latter being a major strength of our study. At least in an acute stage, pathological tissue inflammation and destruction in the musculoskeletal system (and beyond) likely trigger the defensive capacities of predominantly the immune and pain system and urge the organism to escape/avoid this imminent or actual threat ${ }^{15,39}$. For some patients, these fearful beliefs may emanate from direct respondent and operant learning of the altered relationship between biomechanical loading and pain/disease processes in $\operatorname{axSpA}^{1}$. Depending on the motivational context $^{40}$, adaptive protective posture and movement behaviors (e.g., limiting the range ${ }^{41,42}$, amount ${ }^{37}$, or velocity $^{41}$ of movement) develop that may lead to disability, as observed in our study. Controlling disease processes will likely result in spontaneous recovery of these adaptive behaviors. In other patients, however, these fearful concerns become incongruent with disease processes, resulting in similar but maladaptive protective posture and movement behaviors and their consequences ${ }^{43}$. Possibly, fear overgeneralization to previously neutral cues (e.g., painful back extension spreads to overall painful spinal movements) or operant reinforcement of fear/avoidance (e.g., through observation of other patients' pain, fearful media stories ${ }^{44,45}$, or verbal instruction on the harmfulness of movement by healthcare professionals ${ }^{45}$ ) may inhibit the extinction of these fearful beliefs. Although our mediation analysis revealed TSK-11 as a partial mediator of pain toward activity limitations, the underlying processes leading to $\mathrm{FOM} /(\mathrm{R}) \mathrm{I}$ and its resolution in axSpA merit further study. Also, the statistical identification and validation of the proposed subgroups and piloting stratified care interventions in axSpA will be the focus of our future research in this area. For now, we can only recommend screening for FOM/(R)I in clinical practice.

There are some limitations to our study that need to be acknowledged. Although sequential relationships cannot be ascertained, the cross-sectional design was appropriate to evaluate psychometric properties, and was able to show a significant association between FOM/(R)I and activity limitations. A longitudinal perspective is needed, however, to extend the pilot mediation analysis toward a full analysis of the FAM predictions over time ${ }^{46}$.

Another limitation of our study is that magnetic resonance imaging (MRI) or the Ankylosing Spondylitis Disease Activity Score (ASDAS) and standard radiographs were not included to define, respectively, disease activity and bone formation. To date, there is no gold standard for the assessment of disease activity in ax $\operatorname{SpA}^{24}$. Although MRI is highly attractive owing to its reliability and objectivity ${ }^{47}$, its role is mostly established for diagnostic purposes ${ }^{24}$ because issues of validity arise when quantifying the amount of disease activity ${ }^{48}$. The ASDAS, still under development during our study, was not included, but similar associations between BASFI-ASDAS and BASFI-BASDAI were reported $^{49}$. In our study, we were primarily interested in the relative contribution of $\mathrm{FOM} /(\mathrm{R}) \mathrm{I}$ to BASFI compared to different definitions of disease activity and spinal mobility. We observed an increased contribution of TSK-11 (from $29 \%$ to $60 \%$ in comparison to known major determinants of disease activity and spinal mobility ${ }^{38}$ ) when using the less patient-reported disease activity outcomes CRP and PGDA. Because of the known relationship between patient-reported disease activity and psychological factors ${ }^{50}$ and given that our data confirmed TSK-11 as only a partial mediator between spinal pain and BASFI, we suspected that part of the BASDAI, BASDAIpain, or BASDAIinf effect covaries with TSK-11 despite the absence of collinearity in all models (VIF very low). Increased importance of TSK11 in the CRP/PGDA model and the common/shared variance between BASDAI or BASDAIpain or BASDAIinf and TSK-11 consistently revealed in the commonality analysis also confirmed this idea. In contrast, spinal mobility showed a quite low correlation and common variance with TSK-11 and a similar proportional contribution in comparison to TSK-11 across models. Thus, we can be confident that spinal mobility indeed mimicked bone formation, which is in line with prior research ${ }^{25}$. Nevertheless, future research should study these effects in models including different imaging outcomes.

Our study established the TSK-11's scaling assumptions and construct validity as essential psychometric properties in axSpA. Also, an important role for FOM/(R)I in explaining activity limitations was confirmed in addition to the major contributions of spinal mobility impairment and disease activity in axSpA. Future research should focus on a better understanding of $\mathrm{FOM} /(\mathrm{R}) \mathrm{I}$ and avoidance behavior in the development and maintenance of disability in patients with axSpA, which likely will lead to novel and more targeted patient-centered multidimensional interventions for patients with this rheumatic disease.

\section{ACKNOWLEDGMENT}

The authors thank all participants and all staff members of UZ Leuven who operationally contributed to this study.

Personal non-commercial use only. The Journal of Rheumatology Copyright @ 2018 . All rights reserved. 


\section{ONLINE SUPPLEMENT}

Supplementary material accompanies the online version of this article.

\section{REFERENCES}

1. McGonagle D, Lories RJ, Tan AL, Benjamin M. The concept of a "synovio-entheseal complex" and its implications for understanding joint inflammation and damage in psoriatic arthritis and beyond. Arthritis Rheum 2007;56:2482-91.

2. Luyten FP, Lories RJ, Verschueren P, de Vlam K, Westhovens R. Contemporary concepts of inflammation, damage and repair in rheumatic diseases. Best Pract Res Clin Rheumatol 2006;20:829-48.

3. Maksymowych WP, Crowther SM, Dhillon SS, Conner-Spady B, Lambert RG. Systematic assessment of inflammation by magnetic resonance imaging in the posterior elements of the spine in ankylosing spondylitis. Arthritis Care Res 2010;62:4-10.

4. Rudwaleit M, van der Heijde D, Landewe R, Listing J, Akkoc N, Brandt J, et al. The development of Assessment of SpondyloArthritis international Society classification criteria for axial spondyloarthritis (part II): validation and final selection. Ann Rheum Dis 2009;68:777-83.

5. Rudwaleit M, Metter A, Listing J, Sieper J, Braun J. Inflammatory back pain in ankylosing spondylitis: a reassessment of the clinical history for application as classification and diagnostic criteria. Arthritis Rheum 2006;54:569-78.

6. Dagfinrud H, Kjeken I, Mowinckel P, Hagen KB, Kvien TK. Impact of functional impairment in ankylosing spondylitis: impairment activity limitation, and participation restrictions. J Rheumatol 2005;32:516-23.

7. Boonen A, Braun J, van der Horst Bruinsma IE, Huang F, Maksymowych W, Kostanjsek N, et al. ASAS/WHO ICF Core Sets for ankylosing spondylitis (AS): how to classify the impact of AS on functioning and health. Ann Rheum Dis 2010;69:102-7.

8. Maxwell LJ, Zochling J, Boonen A, Singh JA, Veras MM, Tanjong Ghogomu E, et al. TNF-alpha inhibitors for ankylosing spondylitis. Cochrane Database Syst Rev 2015;4:CD005468.

9. Baeten D, Baraliakos X, Braun J, Sieper J, Emery P, van der Heijde $\mathrm{D}$, et al. Anti-interleukin-17A monoclonal antibody secukinumab in treatment of ankylosing spondylitis: a randomised, double-blind, placebo-controlled trial. Lancet 2013;382:1705-13.

10. Arends S, Lebbink HR, Spoorenberg A, Bungener LB, Roozendaal $\mathrm{C}$, van der Veer $\mathrm{E}$, et al. The formation of autoantibodies and antibodies to TNF-alpha blocking agents in relation to clinical response in patients with ankylosing spondylitis. Clin Exp Rheumatol 2010;28:661-8.

11. Arends S, Brouwer E, van der Veer E, Groen H, Leijsma MK, Houtman PM, et al. Baseline predictors of response and discontinuation of tumor necrosis factor-alpha blocking therapy in ankylosing spondylitis: a prospective longitudinal observational cohort study. Arthritis Res Ther 2011;13:R94.

12. Kiltz U, van der Heijde D, Boonen A, Braun J. The ASAS Health Index (ASAS HI) - a new tool to assess the health status of patients with spondyloarthritis. Clin Exp Rheumatol 2014;32:S-105-8.

13. Brionez TF, Assassi S, Reveille JD, Learch TJ, Diekman L, Ward MM, et al. Psychological correlates of self-reported functional limitation in patients with ankylosing spondylitis. Arthritis Res Ther 2009;11:R182.

14. Martindale J, Smith J, Sutton CJ, Grennan D, Goodacre L, Goodacre JA. Disease and psychological status in ankylosing spondylitis. Rheumatology 2006;45:1288-93.

15. Vlaeyen JW, Linton SJ. Fear-avoidance model of chronic musculoskeletal pain: 12 years on. Pain 2012;153:1144-7.

16. Woods MP, Asmundson GJ. Evaluating the efficacy of graded in vivo exposure for the treatment of fear in patients with chronic back pain: a randomized controlled clinical trial. Pain 2008;136:271-80.
17. Leeuw M, Goossens ME, van Breukelen GJ, de Jong JR, Heuts PH, Smeets RJ, et al. Exposure in vivo versus operant graded activity in chronic low back pain patients: results of a randomized controlled trial. Pain 2008;138:192-207.

18. Lööf H, Demmelmaier I, Henriksson EW, Lindblad S, Nordgren B, Opava $\mathrm{CH}$, et al. Fear-avoidance beliefs about physical activity in adults with rheumatoid arthritis. Scand J Rheumatol 2015;44:93-9.

19. Mielenz TJ, Edwards MC, Callahan LF. First item response theory analysis on Tampa Scale for Kinesiophobia (fear of movement) in arthritis. J Clin Epidemiol 2010;63:315-20.

20. Sieper J, van der Heijde D, Landewe R, Brandt J, Burgos-Vagas R, Collantes-Estevez E, et al. New criteria for inflammatory back pain in patients with chronic back pain: a real patient exercise by experts from the Assessment of SpondyloArthritis international Society (ASAS). Ann Rheum Dis 2009;68:784-8.

21. von Elm E, Altman DG, Egger M, Pocock SJ, Gotzsche PC, Vandenbroucke JP, et al. The Strengthening the Reporting of Observational Studies in Epidemiology (STROBE) statement: guidelines for reporting observational studies. Lancet 2007;370:1453-7.

22. Calin A, Garrett S, Whitelock H, Kennedy LG, O'Hea J, Mallorie P, et al. A new approach to defining functional ability in ankylosing spondylitis: the development of the Bath Ankylosing Spondylitis Functional Index. J Rheumatol 1994;21:2281-5.

23. Van Tubergen A, Debats I, Ryser L, Londono J, Burgos-Vargas R, Cardiel $\mathrm{MH}$, et al. Use of a numerical rating scale as an answer modality in ankylosing spondylitis-specific questionnaires. Arthritis Rheum 2002;47:242-8.

24. Sieper J, Rudwaleit M, Baraliakos X, Brandt J, Braun J, Burgos-Vargas R, et al. The Assessment of SpondyloArthritis international Society (ASAS) handbook: a guide to assess spondyloarthritis. Ann Rheum Dis 2009;68 Suppl 2:ii1-44.

25. Castro MP, Stebbings SM, Milosavljevic S, Bussey MD. Construct validity of clinical spinal mobility tests in ankylosing spondylitis: a systematic review and meta-analysis. Clin Rheumatol 2016;35:1777-87.

26. Jenkinson TR, Mallorie PA, Whitelock HC, Kennedy LG, Garrett SL, Calin A. Defining spinal mobility in ankylosing spondylitis (AS). The Bath AS Metrology Index. J Rheumatol 1994;21:1694-8.

27. Woby SR, Roach NK, Urmston M, Watson PJ. Psychometric properties of the TSK-11: a shortened version of the Tampa Scale for Kinesiophobia. Pain 2005;117:137-44.

28. Roelofs J, van Breukelen G, Sluiter J, Frings-Dresen MH, Goossens M, Thibault P, et al. Norming of the Tampa Scale for Kinesiophobia across pain diagnoses and various countries. Pain 2011;152:1090-5.

29. Velthuis MJ, Van den Bussche E, May AM, Gijsen BC, Nijs S, Vlaeyen JW. Fear of movement in cancer survivors: validation of the modified Tampa scale of kinesiophobia-fatigue. Psychooncology 2012;21:762-70.

30. Streiner DL, Norman GR. Health measurement scales: a practical guide to their development and use. New York: Oxford University Press; 1995.

31. Gandek B, Ware JE Jr., Aaronson NK, Alonso J, Apolone G, Bjorner $\mathrm{J}$, et al. Tests of data quality, scaling assumptions, and reliability of the SF-36 in eleven countries: results from the IQOLA Project. International Quality of Life Assessment. J Clin Epidemiol 1998;51:1149-58.

32. Nunnally JC, Bernstein NH. Psychometric theory, 3rd ed. New York: McGraw Hill; 1994.

33. Kraha A, Turner H, Nimon K, Zientek LR, Henson RK. Tools to support interpreting multiple regression in the face of multicollinearity. Front Psychol 2012;3:44.

34. Hayes AF; Little TD, editor. Introduction to mediation, moderation, and conditional process analysis: a regression-based approach. New York: Guilford Press; 2013. 
35. Roelofs J, Sluiter JK, Frings-Dresen MH, Goossens M, Thibault $P$, Boersma K, et al. Fear of movement and (re)injury in chronic musculoskeletal pain: Evidence for an invariant two-factor model of the Tampa Scale for Kinesiophobia across pain diagnoses and Dutch, Swedish, and Canadian samples. Pain 2007;131:181-90.

36. Berenbaum F, Chauvin P, Hudry C, Mathoret-Philibert F, Poussiere $\mathrm{M}$, De Chalus T, et al. Fears and beliefs in rheumatoid arthritis and spondyloarthritis: a qualitative study. PLoS One 2014;9:e114350.

37. Swinnen TW, Scheers T, Lefevre J, Dankaerts W, Westhovens R, de Vlam K. Physical activity assessment in patients with axial spondyloarthritis compared to healthy controls: a technology-based approach. PLoS One 2014;9:e85309.

38. Landewe R, Dougados M, Mielants H, van der Tempel H, van der Heijde D. Physical function in ankylosing spondylitis is independently determined by both disease activity and radiographic damage of the spine. Ann Rheum Dis 2009;68:863-7.

39. Meulders A, Vlaeyen JW. The acquisition and generalization of cued and contextual pain-related fear: an experimental study using a voluntary movement paradigm. Pain 2013;154:272-82.

40. Claes N, Crombez G, Vlaeyen JW. Pain-avoidance versus reward-seeking: an experimental investigation. Pain 2015; 156:1449-57.

41. Trost Z, France CR, Sullivan MJ, Thomas JS. Pain-related fear predicts reduced spinal motion following experimental back injury. Pain 2012;153:1015-21.

42. Machado P, Landewe R, Braun J, Hermann KG, Baker D, van der Heijde D. Both structural damage and inflammation of the spine contribute to impairment of spinal mobility in patients with ankylosing spondylitis. Ann Rheum Dis 2010;69:1465-70.
43. Slade PD, Troup JD, Lethem J, Bentley G. The fear-avoidance model of exaggerated pain perception-II. Behav Res Ther 1983;21:409-16.

44. Helsen K, Vlaeyen JW, Goubert L. Indirect acquisition of pain-related fear: an experimental study of observational learning using coloured cold metal bars. PLoS One 2015;10:e0117236.

45. Buchbinder R, Jolley D, Wyatt M. 2001 Volvo Award Winner in Clinical Studies: Effects of a media campaign on back pain beliefs and its potential influence on management of low back pain in general practice. Spine 2001;26:2535-42.

46. Gheldof EL, Crombez G, Van den Bussche E, Vinck J, Van Nieuwenhuyse A, Moens G, et al. Pain-related fear predicts disability, but not pain severity: a path analytic approach of the fear-avoidance model. Eur J Pain 2010;14:870 e1-9.

47. Maksymowych WP, Lambert RG, Brown LS, Pangan AL. Defining the minimally important change for the Spondyloarthritis Research Consortium of Canada spine and sacroiliac joint magnetic resonance imaging indices for ankylosing spondylitis. J Rheumatol 2012;39:1666-74.

48. Gong Y, Zheng N, Chen SB, Xiao ZY, Wu MY, Liu Y, et al. Ten years' experience with needle biopsy in the early diagnosis of sacroiliitis. Arthritis Rheum 2012;64:1399-406.

49. Di Carlo M, Lato V, Carotti M, Salaffi F. Clinimetric properties of the ASAS health index in a cohort of Italian patients with axial spondyloarthritis. Health Qual Life Outcomes 2016;14:78.

50. Brionez TF, Assassi S, Reveille JD, Green C, Learch T, Diekman L, et al. Psychological correlates of self-reported disease activity in ankylosing spondylitis. J Rheumatol 2010;37:829-34. 